\title{
Changes And New Constraints In The Competition Rules Enforcement Due To Accession: The Perception Of The Romanian Companies
}

Alina Mihaela Dima, Academy of Economic Studies, Bucharest, Romania

\begin{abstract}
Many times, in the attempt to win or to maintain an advantageous position on the market, the economic agent will use a whole arsenal of practices (inclusively and mostly from the marketing field), most of them anticompetitive, with a negative impact on the business environment, which also affects the well-being of the consumer. The policy in the field of competition is the one that defines these types of behaviour and penalizes them depending on the importance of their negative impact, by creating a complex and coherent legislative and institutional mechanism. The right enforcement of the competition policy at the national level is the key in this process, but this should be coordinated with the regional and international objectives and regulations in this field. Romania is facing a double challenge: on the one side, it had to set up a competition policy, which was almost ignored before the'90s, on the other side, it had to comply, recently, with high standards in the field, as an EU candidate. Now, as a member state, the promotion of a competition culture becomes a must, along with the design of an adequate system of information and knowledge dissemination for all of those involved. The paper is based on a original and qualitative research and aims at emphasising the increased necessity of the promotion of a competition culture for the competitiveness of the Romanian business environment on the European level in the new context of accession. This will help Romanian business to face the competition challenges within a more extended single European market, as an essential issue of the free market economy status recently granted, and accordingly to the most important EU objectives set up at Lisabon to become the most competitive economy in the world up to 2010.
\end{abstract}

Keywords: competition policy, business environment, internal market, competitiveness

\section{INTRODUCTION}

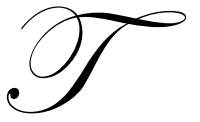

he competition law of the EU responds to Europe's mid-century economic conditions. Its development, driven by the imperative of market integration, profited from the symbiosis between the protection of competition and the promotion of open trade. (Wise, 2005). Community competition law is undergoing a deep transition, after moving beyond the initial goals of opening markets and establishing a competition culture to become a mature, comprehensive enforcement structure centred on the European Commission. The substantive principles, which the Community institutions have developed, have become a common legal framework shared with national laws of the Member States.

The EC Treaty makes competition a principal goal, but it does not elaborate what this concept means. The activities prescribed for the Community institutions include inter alia the establishment of "an internal market characterized by the abolition, as between Member States, of obstacles to the free movement of goods, persons, services and capital," and "a system ensuring that competition in the internal market is not distorted. "The 
Community and its Member States are to adopt a coordinated economic policy based on "an open market economy with free competition." These parts of the Treaty thus set out the goal of free and undistorted competition for the Community's internal market. The basic rules of Articles 81-87 do not limit the choice of policy goals. They do make clear that the competition rules address government measures as well as private conduct.

The accession of the countries of Central and Eastern Europe to the Union could further complicate the enforcement of competition law. Businesses that operate across the whole EU need to meet the requirements of a further 12 different sets of competition laws. These countries have already adopted the acquis communautaire, the existing body of EU laws, which contains detailed provisions on competition policy. But, even if they have the laws in place, few of them have the legal and economic expertise necessary to enforce competition laws rigorously. For example, one year before enlargement, the Commission noted that while some progress has been made in anti-trust enforcement state aid controls are in general, far from satisfactory. The new countries need to address these problems urgently and continuously to ensure that their accession to the EU is fully and provides clear advantages.

Promoting an authentic culture in the field of competition is considered to be a very important issue in the process of enforcement the rules existing on the market economy, together with using specific instruments for fighting anti-competitive practices and for controlling economic concentration and state grants. Thus, competition policy must be known and understood by everyone involved in the economic life, and this cannot be achieved without consciously applying transparency and non-discrimination principles. It is necessary therefore, besides knowing "the rules of the game", to know the procedures applied by the Competition Council until ruling (Berinde, 2000). The general public, the business environment, as well as all the public authorities, must understand the Competition Council's role in maintaining the market economy functional. In addition, they must know the methods by which this Council takes actions and the goal of consciously applying the competition norms: creating and developing a competition environment that protects the consumers, so that they can benefit from the advantages offered by an honest competition.

Furthermore, the economic agents must be informed about and must know both methods by which they can be protected by legislation in case they fall victims to some sort of anti-competitive practices, and the risks they expose themselves to in case they break the rules. They must be aware of the fact that only by knowing the legislation very well they can be protected by the law: first of all they must know which are those forbidden practices as not to infringe upon them, thus avoiding fines and sanctions; then, every time they feel threatened on the market by the actions of the companies infringing the law, they can file a complaint with a view to putting an end to these practices that are detrimental to their activity. Promoting competition culture values and consciously applying its principles produces disadvantages only for the inefficient companies, while for the entire economy and consumers, the results, as demonstrated in tens of countries, are those of promoting the technical progress, of efficiently allocating resources, of developing the private sector and of improving the social welfare.

Although these principles can be applied in any field, transparency is especially requested in the field of competition (Miron, 1998), because the legislation must be understood as a basic framework the competition authorities have at their disposal, and its enforcement depends on the case by using specific methods and instruments, Romanian jurisprudence, as well as other countries' jurisprudence. Starting from 1994, EU competition rules are applied to commercial agreements with other states, including Romania (Association Agreements). Generally, the legislation has priority over national legislation, but it is not replaced automatically (Hitris, 2003). The awareness of the mechanisms of the competition policy at a community level and a proper interpretation of them, is by any means a must for the business environment in Romania, especially that the degree of monitoring of the competition customs has increased, because besides the national institution in the field, other institutions have joined in (The European Commission, The European Court of Justice or The Court of First Instance) which can interfere at any moment in order to arrange a certain competition situation on the market in Romania

For the reasons mentioned above, I considered necessary to conduct a qualitative survey amongst the companies in Romania, a survey that may allow to obtain comprehensive valid and valuable information, so as to reach relevant conclusions regarding the degree of knowledge and perception of companies as to the competition policy provisions and the role of competition authority. An insufficient degree of preparing and informing of the 
economic agents on the large market, as that of the European Union market, might create confusion, disorientation and loss of important benefits coming from multiple opportunities of development and expansion. Mc Donald and Dearden (2005) mentioned that EU developed a competition policy to preserve the benefits of a unique market, because the dismantling national barriers for trade could be replaced by other private barriers.

The results of this survey can be used for grounding decisions regarding the role the competition policy should play in defining the company's strategy but also the formative role the Competition Council should play in a country; a country with a relatively instable, volatile, politically influenced business environment, but with an important potential considering the opportunities for expansion and development.

\section{RESEARCH METHODOLOGY}

\section{The Goal And The Objectives Of The Research}

The research has the goal of analysing the degree of knowledge and information of Romanian business environment regarding the competition law and the role played by the Competition Council, an independent institution, autonomous in regulating the mechanisms on the free market by protecting correct competition. Therefore, the objectives of this research can be synthesized as follows:

- The analysis of the knowledge and perception of the business environment as to the Council's activity (identifying the main attributions of this institution, and its principal role, the evaluation of the activity, main reasons for this perception, solutions for improving the activity of the Council proposed by the companies);

- Determining the business environment degree of knowledge and perception about the way in which it will change after EU accession and the factors that will influence these changes.

\section{The Research Method}

According to the type of information resulting from the research, this is a qualitative research, and according to the place of carrying out the research it is an on sight investigation. The qualitative research methods are considered to be the most appropriate data collecting methods, relevant enough to understand the decision making process at companies' level (Carson at al, 1998), the way managers understand the meaning and content of some actions (Jones, 1985), their purpose is rather an explaining than predicting phenomenon (Leavy, 1994) and to rather understand than quantify (Gordon and Langmaid, 1988). According to the functional goal of this research, it is an exploratory investigation, predominantly descriptive, which is aimed at describing and evaluating some coordinates, but also an explanatory investigation, because it tries to analyse the causal relationships existing between certain existent variables.

\section{The Sample Of The Survey}

The studied population consists of the total of all companies in Romania. The Romanian company represents the unit for observation, and the juridical department represents the unit for survey. In the case of smaller enterprises, the general manager was interviewed. In some cases, the questionnaire was filled in by an expert from the marketing department (commercial or sales, depending on the case). In this case, 300 companies in Bucharest were phoned or e-mailed and 100 gave an affirmative reply, thus having an answering rate of $33.33 \%$.

\section{The Method For Collecting Information}

In order to better answer the objectives of the research I chose to get my information by interviewing, using a questionnaire with pre-established questions, which was distributed by the interviewing operators. The information was gathered during February-May 2006 and was perfected, analysed and interpreted during the period AugustSeptember 2006. In accordance to the method of gathering information, the instrument for collecting information 
was established, this being a questionnaire made up of 30 questions, of which 3 were questions for identifying and the rest of them questions of content.

\section{THE RESEARCH RESULTS}

\section{Identifying The Competition Council's Attributions And Role}

According to the provisions of the Competition Law, the Competition Council has as a main goal protecting and stimulating competition, ensuring a normal competition environment, with a view to promoting consumers' needs. $23 \%$ of those who answered have identified this attribution as pertaining to the Competition Council.

Also, 37\% of the respondents have underlined the fact that the Council takes decisions in cases of infringement of the provisions of the Competition Law and that it is an organism of control which, in order to ensure competition on the market, conducts investigations regarding the activity of the economic agents and supervises some of their actions, taking decisions in cases of the Competition Law infringement. Of those who answered the survey, some mentioned as attributions of the Council: sanctioning the anti-competitive practices in order to protect companies on the market (14\%), sanctioning the abuse of a dominant position or monopoly situations (10\%), approving economic concentrations (7\%) and approving, monitoring and other operations related to stare grants $(11 \%)$. Only one respondent mentioned the fact that it takes decisions of giving exempts of individual exception agreements or giving derogations.

At the same time the Competition Council has the following obligations in relation to judicial courts: informs the judicial courts about the cases pertaining to them; follows up on the enforcement of the legal provisions and of other normative acts related to the field of regulating the Competition Law; notifies the Government of the existence of monopoly situations or of other cases which fall under the supervision of the law and suggests taking the necessary measures to rectify the non-compliance; issues notifications for drafts of the normative acts which can have an anticompetitive impact and proposes the modification of those acts which are effect-less; sends out recommendations for adopting measures which may facilitate the development of the market and of competition to the Government and to the other central and local administrations. 3\% of the interviewed companies identified among the Council's attributions the fact that it gives the Government and other public administration organisms recommendations and proposals, and 3\% that it informs the judicial courts and the Government in certain situations about the breaking of the law. Only $2 \%$ mentioned that this institution conducts studies and draws up an annual report concerning its activity and the way in which economic agents and public authorities abide by the norms of competition in its field of activity (another proof of the fact that this report is not known or advertised ); 5\% mentioned that it stands for Romania and that it promotes information and relation exchange between the organizations and the international institutions in the field and that it cooperates with foreign competition authorities and especially with those in the E.U.

$3 \%$ of the respondents mentioned that one of the attributions of the Council is eliminating dumping and establishing a fair price on the market, and $1 \%$ the fact that this institution has played the part of a coordinator in the negotiation of the chapter 6-Competition. $4 \%$ of those interviewed answered that they didn't know the answer to this question. None of the respondents mentioned that the role of the Competition Council as an autonomous administrative authority has two dimensions: a corrective one, as establishing and maintaining a normal competitive environment, and the second one, the preventive dimension of monitoring the markets and the actors which operate on these markets, and ensuring the application of its decisions effectively in accordance to the principle of autonomy.

The distinct pattern of answers, which covers about $90 \%$ of the Council's attributions, does not necessary show the business community knowledge of them. Moreover, $90 \%$ of the companies did not enlist more than 3 attributions of the Council and their answers were frequently unclear (for example, protecting competition, or protection of consumers, or control organism, or establishment of a fair price). This happened because, although a share of those interviewed had heard about the Competition Council without having contact with members of the 
institution, they had a difficult time giving clear and relevant answers, in the end being able to foresee which were the general attributions of this institution.

\section{The Evaluation Of The Competition Council's Activity}

As a result of the survey, almost half of the interviewed companies consider that the activity of the Council is an acceptable one, which reflects more the avoidance in adopting a position and expressing a clear opinion in the matter. This is because companies are not familiar to certain aspects in order for them to make an opinion (good or bad), or because they prove a concerning lack of interest.

Figure 1: Respondents' opinion on the Competition Council's activity in Romania
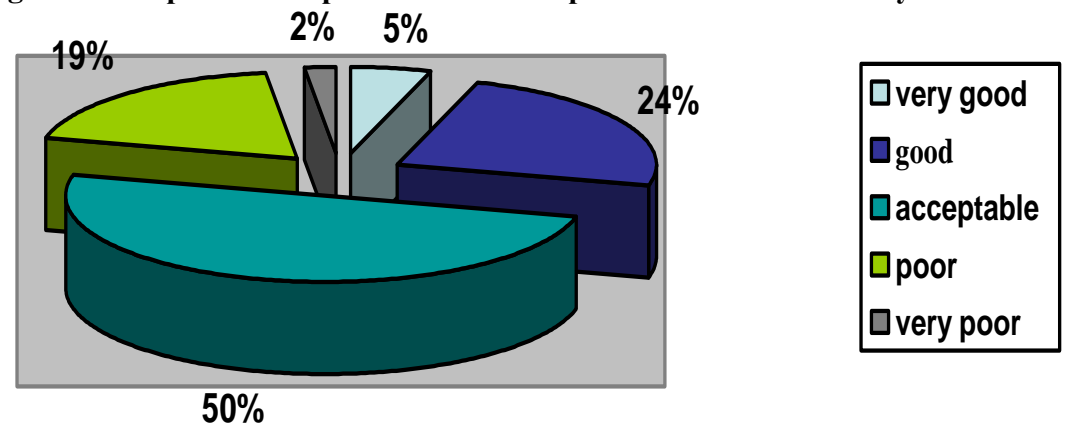

$19 \%$ of those who answered considered that the activity is poor, and $2 \%$ that it is very poor. The most important reasons mentioned by the respondents were: lack of efficiency (does not cover all sectors, reacts with delay, long time to investigate, sanctions are not harsh enough, lack of communication between departments), low degree of informing the population and poor reflection in the media, lack in implementing the law or unfulfilling its attributions given to it by the law, lack of credibility, low image and visibility and political subordination (see table 1).

Table 1: Reasons for evaluation of the Council's activity

\begin{tabular}{|l|c|}
\hline \multicolumn{1}{|c|}{ Reasons for the poor and very poor evaluation of the Council's activity } & Percent of the respondents \\
\hline low activity efficiency & 19 \\
\hline lack of promotion & 12 \\
\hline poor implementation of the law & 8 \\
\hline low credibility, image and visibility & 7 \\
\hline lack of collaboration with the business environment & 7 \\
\hline regulations in the field are nor clear enough & 5 \\
\hline politic subordination & 3 \\
\hline other reasons & 3 \\
\hline
\end{tabular}

There are a number of reasons mentioned by a small number of companies (1-2\%), but which are worth mentioning: the fact that the state aid is given in too many sectors or that it exists in many fields in which there is no real competition, this being eliminated by the existence fixed high prices (notaries, architects), or it is just simulated (fuel), or because there is a monopoly on the market (cable television market). The cases mentioned are just a few situations of the infringement of the Competition Law, to which the Council has adopted a cautious behaviour which runs counter to the role this kind of institution should play on the competition market.

It is noticed that $24 \%$ of the companies considered the Council's activity as being good, and $5 \%$ considered it very good. Despite all these, the arguments presented to sustain this are not conclusive. The Council is an 
organization with attributions, objectives and goals very well defined and although it has yet many aspects to improve, it has succeeded in intervening on the market in some cases of law breaking as in the field of insurance, drug stores, and oil. Furthermore it has prompt reactions in implementing measures, runs fair and objective tests, adopts multiple methods for advertising itself by means of seminars, expert magazines, informative bulletins and it stands for Romania in $24 \%$ of the relationships with other organizations and institutions in the field.

The fact that it exists as an institution and has a mission and a goal or the fact that it represents Romania in relations with other institutions and organizations in the field does not justify appreciating the quality of its actions, neither does the fact that it has succeeded in intervening on the market in some situations (as this was the reason why it was created), considering that in many situations it remained an outsider or it was used as an instrument of politics to interfere on the market.

\section{Ways For Improving The Council's Activity}

Most of the questioned economic agents suggested improving the activity of promoting the Council's activity by correctly informing the population and the business environment of the regulations in the field, a better training of the staff in the institution and its specialization in different fields and areas, moreover increasing the number of inspectors, especially at a local level and introducing specialized services in the fields. Some respondents suggested strengthening the institution's trustfulness by increasing the number of investigating cases, implementing a more rapid way of solving investigations, and reducing bureaucracy; an important aspect is reducing corruption in the institution by granting payment stimulants for inspectors to strengthen control. Furthermore, it is necessary to monitor closely the behaviour of the economic agents, to reduce monopoly situations and state grants, together with ensuring independency and autonomy from a political point of view and improving regulations and instructions in the field of competition. (see table no 2)

The majority of the cases analysed by the competition authorities since their setting up till now have involved the state, through different representatives- including central or local authorities: decisions adopted by the government, orders of different ministers, decisions of local authorities, ways in which different authoritiesespecially at local level, but not exclusively- behaved similar to economic agents or government capital institutions etc. In practice, except for some mergers or acquisitions in some domains, as in cement or beer industry-in all the other important cases investigated by the competition authorities in Romania, the state- covering both dimensionswas more present. This observation emphasizes the important fact that the competition authority must be independent from politics in order for it to fulfil its mission.

Table 2: Companies' proposals for improving the Council's activity

\begin{tabular}{|l|c|}
\hline \multicolumn{1}{|c|}{ Proposals for improving the Council's activity } & Percent of the respondents \\
\hline $\begin{array}{l}\text { Increasing promoting and informing of the population in the business } \\
\text { environment about the regulation in the field and about the Council's activity }\end{array}$ & 60 \\
\hline Better training of the personnel and its increase in number & 24 \\
\hline Reducing monopoly and stat grants & 16 \\
\hline Insuring interdependency and autonomy from a political point of view & 9 \\
\hline Increasing transparency and fairness of law enforcement & 17 \\
\hline $\begin{array}{l}\text { Increasing trustfulness by increasing the number of the investigating cases, a } \\
\text { more rapid solution, and enforcing more severe sanctions }\end{array}$ & 9 \\
\hline Decreasing bureaucracy and corruption & 16 \\
\hline Others & \\
\hline
\end{tabular}

Other solutions coming from a small number of companies include: improving communication and relations with the business environment by creating a expert site which will include useful information about the business environment (2\%), for example important privatizations or auctions, monthly meetings with local employers, with business environment representatives (4\%), organizing seminars in order to explain the legislation, 
and for the Competition Council to have more of a consultative role rather than that of sanctioning one (2\%), as well as improving cooperation with institutions in the field in the EU and on an international level (3\%).

A single company mentioned the necessity for consulting services for companies regarding protection against anti competitive practices. Although the answer does not target improving the Council's activity, it is worth mentioning, as it shows a special interest in the results of the survey. The consulting companies' emerging and developing in the field of competition is actually the key to most companies' survival on an extended market in 2007. Yet, a concern is the fact that only a single company of those interviewed had noticed this problem taking into consideration the fact that most of these companies will have to face competition on EU markets from thousands of companies in the E.U. after 2007, while the European Commission will be the most important authority with sanctioning capacity.

Except the cases in which some companies are under investigation for settlements regarding diminishing competition or dominant position abuse, there must be two-way cooperation between the Competition Council and the business environment. This issue was also underlined by the respondents. This two-way advantageous cooperation will bring forward the necessity of strengthening the companies' capacity to face the competition pressure on the EU market.

In this way the business environment must be aware of the "weapons" it has within the reach of its hand to combat some companies' behaviour in relation to reducing or ceasing of competition. The business environment must understand how the competition authority can help him, by eliminating barriers existing at entering or leaving different countries. Moreover, the business environment must comprehend the role of the competition authority in functioning of the free market mechanisms.

On the other hand, the authority for protecting competition needs the business environment as it cannot take discretionary decisions. Therefore, some clear, simple and transparent rules have to be established and made known to everyone. This thing requires support from everyone and especially from the business communities, which can offer the appropriate institutional framework for promoting competition principles.

\section{The Changes In The Council's Activity After EU Accession}

Regarding the way in which the Competition Council's activity will change after EU accession, the respondents consider that $88 \%$ of its activity will develop, idea that is in accordance to the fact that $71 \%$ of the respondents had evaluated the Council's activity as being acceptable, poor or very poor (and only $24 \%$ considered it to be good, and 5\% very good).

Figure 2: The perception of modifying Competition Council's attributions after EU accession by the Romanian business environment

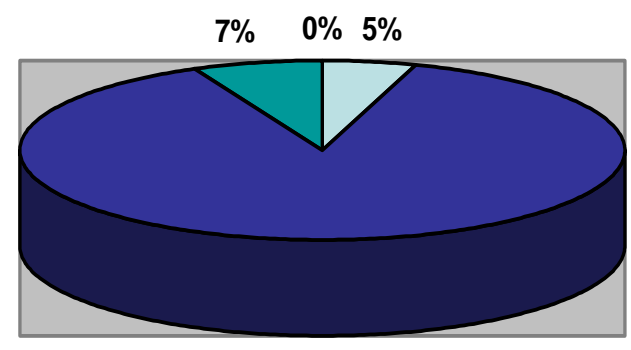

\begin{tabular}{|l|}
\hline it will develop \\
$\square$ it wil diminish \\
$\square$ it will remain the same
\end{tabular}

$88 \%$ 
The reasons why EU accession will allow improving the Council's activity are determined mostly by the necessity of adopting community standards, meaning international standards, and by harmonizing Romanian legislation to EU regulations and institutions. Also, an important factor is the increasing dimensions of the market and consequently the strengthening of competition; the fact that after accession there will be more companies and that the Council will have to reorganize its activity in order to maintain a normal competition environment. The accession will improve and develop cooperation with the EU institutions and correspondent authorities in the member states and involving foreign experts - an important fact that will help Romania strengthen the competition issue.

Other reasons offered in the survey by companies in order to sustain the idea according to which the Council's activity will see an improvement after January 2007 are: reducing the number of state enterprises and monopolies, diminishing state grants and the EU taking all the responsibilities in this field, increasing economic concentrations applicability, diversifying product offers, as well as increasing financing sources.

$7 \%$ of the respondents mentioned the fact that the Council's activity will diminish because of accession, decisions concerning competition will be fore taken by the European Commission, and the Competition Council will become a territorial authority. $5 \%$ of the respondents consider that the Council's activity will remain unchanged at least in the following years, mostly because of corruption and poor personnel training.

Table 3: Reasons for changing the Council activity after accession

\begin{tabular}{|l|c|}
\hline \multicolumn{1}{|c|}{ Reasons why the Council's activity will develop after EU accession } & Percent of respondents \\
\hline necessity of adopting EU standards, namely international standards & 53 \\
\hline extending the market and thus the competition & 14 \\
\hline developing cooperation with similar institution in the EU & 9 \\
\hline Reducing politics influence and increasing transparency in taking decisions & 6 \\
\hline personnel training & 3 \\
\hline improving trustfulness among business communities & 2 \\
\hline others & 7 \\
\hline
\end{tabular}

It is obvious that EU accession will also require modifications in the way decisions are taken between the Competition Council and the European Commission. The European Commission will become the most important decision factor in the field of competition. Despite all this the role of the Council cannot be minimized for it will be the community dimension - the dividing element between anti-competitive aspects, which will belong to the Commission and those pertaining to the Council. From the date of accessing the EU, the process of offering state grants will be transferred from national authorities to the European Commission.

\section{CONCLUSIONS}

The results of this survey can be used for grounding decisions regarding the role the competition policy should play in defining the company's strategy but also the formative role the Competition Council should play in a country; a country with a relatively instable, volatile, politically influenced business environment, but with an important potential considering the opportunities for expansion and development. Taking into account all these aspects, promoting a culture in the field of competition in the framework of the business Romanian environment, is a "sine qua non" requirement and without it the adhesion to the UE is just a simple political exercise. The Competition Council has a determinant role in this process, role that it must redefined in the new context determined by the adhesion to the UE. Also, the Romanian business environment must create new and viable instruments that can offer the recognition of the performances on an extended market, where the fight for supremacy is a state of fact. The role of the consultancy companies in the issue of competition becomes crucial. Recent studies show that very few companies in the Central and Eastern Europe have initiated a competition audit inside the company or have prepared to face increased investigation capabilities of the Competition General Directorate (Business Europe, 2004). 
It should be underlined the fact that the analysis in the field of competition is not simple and does not always lead to clear results and obvious solutions. It must comprise not only the juridical interpretation, but also the economic one and maybe this double analysis could make the competitive phenomenon absorbing and provocative for the scientists, for the business environment, for the authorities, for the academic environment, but also for those who wish to understand and look into this field. Lately there has been mentioned in the literature the existence of a "competition discipline and of a culture in the competition field" as an obligatory and necessary requirement which might allow a deeper accession to the EU (Monti, 2001). If the competition discipline is learned faster by the authorities, and by the economic agents, being the same as the one in the UE, the competition culture is then achieved in time through a series of actions and measures intended to lead to the fulfilling of those requirements. Defining more clearly the competition culture concept, based on the international literature, but also adapted to the real necessities of the Romanian business environment is an important step in this process.

Also, an interference between the culture in the competition field and the organizational culture or the culture in the marketing field is not at all exaggerated, because all of them belong to the same actual trend and have as objective the obtaining of some competitive advantages on the European market, advantages that will allow a better positioning within the market frame and will be a guarantee for accessing properly the European economic field.

In this process of informing and educating, the authority in the competitive domain has limits and restraints of its own, which are determined by the absence of the material and human resources, and on the other hand because its role is more punitive than preventive. Briefly, every economy combines in various proportions constraining force and commitment. The general result depends on the each nation's characteristics. If the constraint is useless or if everyone observes effectively the rules of the game, the economy is functioning better. (Didier, 1989). Therefore, in order to be able to face competitive challenges on the unique market, companies have to make use of the consulting companies' services on competition issues, which will take for all the business decisions to be perfectly legal and compatible with the provisions of the competition law. Consulting an activity on competition issues is just the beginning, but which will probably increase in the next 2 years following the accession, when the business environment will acknowledge the necessity of such a service, in lack of an expert department on competition issues.

Thus, to publish business environment competition guidelines, as final objective, constitutes a need at this moment and it will become an essential element in the educational process of the business environment. This will promote the competition culture at an organizational level, will provide necessary steps to coordinate the general strategy with the objectives of the competition policy and it will contribute to the efficiency increase of the company as a whole. These guidelines will help the business environment representatives to better understand the competition mechanism and how to internally organize the competition audit. On the other side, it will constitute a relevant support for the academic environment in order to organize some specialized courses and will constitute also relevant reference, for those who teach, or learn or want to better understand the single market mechanism.

Within the process of promoting the competition culture, the educational process has an essential part. The establishment of some partnerships between the education and the business field could represent the key in this process, these problems coming from the lack of competition skills of Romanian companies. Introducing some disciplines, in some universities with an economic profile, can contribute to the quality improvement of the education itself, by orientation and adaptation to the requirements and real needs of the business environment, sine qua non condition of the Bologna process

\section{REFERENCES}

1. Ashton, J.K., Pressey, A. (2007). The regulatory perception of the marketing function: an interpretation of UK Competition Authority investigations 1950-2005, CCP working paper 07-1

2. Ball, D.A., McCulloch, W.H. (1996). International Business. The challenge of global competition, sixth edition, the McGraw-Hill Companies, Inc.

3. Bannerman E. (2002).The Future of EU Competition Policy, Centre for European Reform.

4. Berinde, M. (2000). The White Book of Competition, Competition Council Romania 
5. Dima, A., Vasilache, S. (2007), The competition policy at the crossroads: the new challenges on the enlargement process, European union at the crossroads: the need for constitutional and economic changes, edited by Justyna Maliszerwska-Nienartowicz, Jean Monnet Centre for European Studies Nicolaus Copernicus University in Torun, Poland

6. Dima, A. (2007). Competition challenges for Romanian business environment, Management \& Marketing Journal, Economica publishing house, no 1

7. Egge, M.G., (2001). The harmonization of competition laws worldwide, Richmond Journal of Global Law and Business, vol. 2:1

8. $\quad$ El-Agraa, A.M. (2004). The European Union. Economics and policies, seventh edition, Prentice Hall, Pearson Education Limited

9. European Commission (2003). XXXIInd Report on Competition Policy 2002, Brussels/Luxembourg

10. European Commission (2004). XXXIIInd Report on Competition Policy 2003, Brussels, 04.06.2004, SEC(2004)658 final

11. Fishwick, F. (1993). Making sense of Competition Policy, The Cranfield Management Research Series

12. Gal S. (2004). Market Conditions Under the Magnifying Glass: General Prescriptions for Optimal Competition Policy for Small Market Economies, New York University Center for Law and Business.

13. Harrison, A.L., 2000, International business: Global competition from a European perspective, Oxford University Press, New York

14. Hitris, T. (2003). European Union Economics, fifth edition, Prentice Hall, Pearson Education Limited

15. Hoekman, B., (World Bank); Holmes, P. (Sussex University). (1999). Competition Policy, Developing Countries and the WTO, September, FEEM Working Paper No. 66-99

16. ICN Working Group on Capacity Building and Competition Policy Implementation ( 2003). Capacity building and technical assistance: building credible competition authorities in developing and transition countries, ICN 2nd Annual Conference, Merida, Mexico, 23-25 June

17. Kerber W., Budzinski O. (2004). Towards a Differentiated Analysis of Competition Laws, German Working Papers in Law and Economics No. 12

18. Kist, W. (2003). Antitrust enforcement: deterrence and leniency in an enlarged European Union, Tokyo, 4 November

19. Kroes, N. (2005). Competition in the European Union - the Case for Romania, European Institute of Romania, Bucharest, $12^{\text {th }}$ May

20. Krugman, P.R.,Obstfeld, M. (2003). International Economics. Theory and policy, International edition, World Student Series

21. Lachmann, W. (Nuremberg University, Germany) (1999). The development dimension of competition law and policy, UNCTAD series on issues in competition law and policy, United Nation

22. Lorentzen J., Mollgaard P., (2002). Competition Compliance: Limits to Competition Policy Harmonization in EU Enlargement, Copenhagen Business School.

23. Miron, D. (1998). Economics of European Integration, ASE Publishing House

24. Monti, M. (2001). Enforcement of competition policy - case for the accession negotiations and for developing a real competition culture, 7-th Annual Competition Conference between Candidate countries and the European Commission, Ljubljana, Slovenia, 17-19 June

25. Monti, M. (2002). EU Competition Policy, Fordham Annual Conference on International Antitrust Law \& Policy, New York, 31 October

26. OECD/Centre for Co-operation with non-members, Directorate for Financial, Fiscal and Enterprise Affairs, (2004). Challenges/Obstacles faced by competition authorities in achieving greater economic development through the promotion of competition, Global Forum on Competition, Contribution from Poland, session II, 9 February, CCNM/GF/COMP/WD(2004)32

27. Parasuraman, A. (1991). Marketing Research, 2nd edition, Addison-Wesley Publishing Company, Inc.

28. Pinon, A. (1994). Guide des affaires dans le marche unique europeen, SEFI

29. Singh A. (2002). Competition and Competition Policy in Emerging Markets: International and Developmental Dimensions, G-24 Discussion Paper Series No. 18, March

30. Stuyck, J. (2005). EC Competition Law After Modernisation: More Than Ever in the Interest of Consumers, Journal of Consumer Policy, vol.28, pp.1-30

31. Treaty Establishing the European Community, as Amended by Subsequent Treaties, Rome, 25 March 1957

32. Wise, M. (1998). Background report on the role of competition policy in regulatory reform, OECD's Competition Law and Policy Committee

33. Woods, N. (2000). The political economy of globalization, Macmillan Press Ltd 